\title{
Nutritional quality improvement of soybean meal by Bacillus velezensis and Lactobacillus plantarum during two-stage solid- state fermentation
}

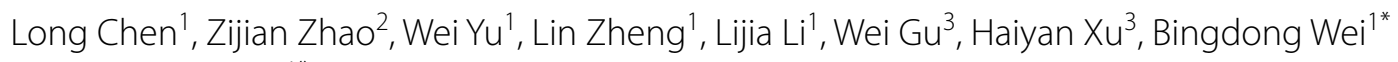
and Xiaogang Yan ${ }^{1 *}$

\begin{abstract}
Bacillus velezensis is widely used for agricultural biocontrol, due to its ability to enhance plant growth while suppressing the growth of microbial pathogens. However, there are few reports on its application in fermented feed. Here, a two-stage solid-state fermentation process using Bacillus velezensis followed by Lactobacillus plantarum was developed to degrade antinutritional factors (ANFs) and improve soybean meal (SBM) nutrition for animal feed. The process was evaluated for performance in degrading SBM antinutritional factors, dynamic changes in physicochemical characteristics, microorganisms and metabolites. After two-stage fermentation, degradation rates of glycinin and $\beta$-conglycinin contents reached $78.60 \%$ and $72.89 \%$, respectively. The $\mathrm{pH}$ of fermented SBM (FSBM) decreased to $4.78 \pm 0.04$ and lactic acid content reached $183.38 \pm 4.86 \mathrm{mmol} / \mathrm{kg}$. NSP-degrading enzymes (Non-starch polysaccharide, NSPases) and protease were detected from the fermented product, which caused the changed microstructure of SBM. Compared to uninoculated SBM, FSBM exhibited increased proportions of crude protein $(51.97 \pm 0.44 \%$ vs. 47.28 $\pm 0.34 \%)$, Ca, total phosphorus (P), and trichloroacetic acid-soluble protein (11.79 $\pm 0.13 \%$ vs. $5.07 \pm 0.06 \%)$. Additionally, cellulose and hemicellulose proportions declined by $22.10 \%$ and $39.15 \%$, respectively. Total amino acid content increased by 5.05\%, while the difference of AA content between the $24 \mathrm{~h}, 48 \mathrm{~h}$ and $72 \mathrm{~h}$ of fermentation was not significant $(P>0.05)$. Furthermore, FSBM also showed antibacterial activity against Staphylococcus aureus and Escherichia coli. These results demonstrated that two-stage SBM fermentation process based on Bacillus velezensis 157 and Lactobacillus plantarum BLCC2-0015 is an effective approach to reduce ANFs content and improve the quality of SBM feed.
\end{abstract}

Keywords: Bacillus velezensis, Antinutritional factors, Soybean meal, Lactobacillus plantarum, Two-stage fermentation

*Correspondence: weibingdong@dlut.edu.cn; yanxiaogang1977@163.com ${ }^{1}$ Institute of Animal Nutrition and Feed, Jilin Academy of Agricultural Sciences, No. 186 Dong Xinghua Street, Gongzhuling 136100, Jilin, China Full list of author information is available at the end of the article

\section{Key points}

- Bacillus velezensis plays a key role during two-stage solid-state fermentation

- Fermentation with B. velezensis and L. plantarum improves SBM quality for feed use

- As a novel qualified presumption of safety (QPS) strain, B. velezensis will have a broad application prospect in food and feed industry. 


\section{Introduction}

Soybean meal (SBM) is the most common source of plant protein used by the food and feed industries. However, glycinin and $\beta$-conglycinin, the main antigenic proteins in SBM, comprise about $30 \%$ and $40 \%$ of total SBM protein, respectively (Maruyama et al. 2000). When consumed by young piglets, these proteins have been shown to induce hypersensitivity that leads to malabsorption syndrome, growth depression, and diarrhea (Shi et al. 2017a). Furthermore, non-starch polysaccharides (NSP), mainly consisting of cellulose, hemicellulose, and pectin, are also found in SBM and have been implicated as causative factors of intestinal disorders in weanling piglets (Shi et al. 2017b). Notably, the generation of fermented SBM (FSBM) by addition of microorganisms, such as Rhizopus oligosporus, Aspergillus oryzae, Lactobacillus brevis, or Bacillus subtilis, may improve SBM nutritional quality by removing antinutritional factors (ANFs) that are detrimental to livestock, while also enhancing bioavailability of nutritional components (Feng et al. 2007; Hong et al. 2004; Wang et al. 2020).

In recent years, $B$. velezensis has been newly reclassified taxonomically as a distinct species, as supported by results of numerous studies employing average nucleotide identity (ANI), DNA-DNA hybridization (DDH), and core-genome-based phylogenetic analyses that phylogenetically distinguish it from Bacillus methylotrophicus, Bacillus amyloliquefaciens subsp. plantarum, and Bacillus oryzicola (Dunlap et al. 2016). However, phylogenetic analysis has also revealed that Bacillus velezensis, Bacillus amyloliquefaciens, and Bacillus siamensis were clustered tightly together to form the "operational group Bacillus amyloliquefaciens" (Fan et al. 2017). This classification scheme is interesting in that it reflects the characteristics of $B$. velezensis that make this species widely applicable to biocontrol applications (Ye et al. 2018), such as commercial biofertilizers and biopesticides that currently employ strains SQR9 (Zhang et al. 2015), 9912D (Pan et al. 2017), LM2303 (Chen et al. 2018c), and FZB42 (Fan et al. 2018). Meanwhile, numerous recent studies and reports have supported use of $B$. velezensis in areas of biocontrol and plant growth promotion (Adeniji et al. 2019). In our previous study, $B$. velezensis 157 had been identified, characterized, and shown to exhibit broad spectrum antagonistic activity toward pathogenic microbes, while also exhibiting various needed lignocellulolytic activities. Meanwhile, SBM has been shown to serve as the most efficient solid-state fermentation (SSF) substrate for B. velezensis 157 (Chen et al. 2018b). Therefore, the ability of B. velezensis 157 to degrade ANFs and improve nutritional quality of SBM warrants further exploration, especially as part of a twostage fermentation strategy combining both aerobic and anaerobic SSF (first stage, aerobic; second stage, anaerobic fermentation) to ultimately degrade ANFs and enhance SBM nutritional value. To date, only a few studies have already been reported for the processing of agro-industrial waste using pairs of organisms to optimize the quality of fermented feed, such as Bacillus subtilis and Enterococcus faecium (Shi et al. 2017a), Bacillus subtilis and Saccharomyces cerevisiae (Chen et al. 2009), and Bacillus subtilis and Bacillus coagulans (Yeh et al. 2018). However, applications involving feed fermentation by $B$. velezensis have not yet been reported and potential beneficial effects of fermentation on ANFs, dynamic changes in physicochemical characteristics, microorganisms and metabolites of SBM during a novel two-stage SSF process warrant further investigation. In addition, $B$. velezensis can be recommended for the QPS list with the qualification 'absence of toxigenic potential and absence of aminoglycoside production ability, which has a broad application prospect in feed additive and fermentation feed industry (Koutsoumanis et al. 2020a, b).

In the present study, SBM was inoculated with $B$. velezensis 157 during the first fermentation stage to remove ANFs from SBM. Next, the addition of $L$. plantarum BLCC2-0015, which has greater acidic capacity than $B$. velezensis, to induce second stage fermentation promoted lactic acid production and reduced the $\mathrm{pH}$ of inoculated SBM. During this two-stage fermentative process, microorganisms and metabolites, ANFs, and chemical composition profiles of uninoculated versus inoculated SBM were characterized and compared.

\section{Materials and methods}

\section{Microorganisms and basal substrate}

Bacillus velezensis 157 had been isolated from Eucommia ulmoides bark and was shown to exhibit various lignocellulolytic activities suited to SSF conversion of agroindustrial waste, which was collected in China Center for Type Culture Collection (M2017475). L. plantarum BLCC2-0015 (CTCC number M2015126) was obtained from Baolai-leelai Bio-tech Co., Ltd. (Taian, China) and is a widely accepted feed additive (originally isolated from pickles) that is used in mixed corn-soybean meal feed. In addition, Staphylococcus aureus ATCC25923 and Escherichia coli ATCC25922 were used as indicator organisms provided by the Institute of Animal Nutrition and Feed, Jilin Academy of Agricultural Sciences, China. Dried and corticate soybean meal (purchased from a local market in Gongzhuling, China) was sieved through a 40-mesh sieve prior to SSF.

\section{Protein degradation capacity}

The protein degradation capacity of $B$. velezensis 157 and L. plantarum BLCC2-0015 were measured using the agar 
well diffusion method. The crude supernatant of candidate strains were prepared according to the method (Wongputtisin et al. 2012). Subsequently, the supernatants were determined using a soybean antigenic protein screening plate described by Liu. et al. (2007).

\section{Preparation of fermented soybean meal}

Two-stage fermentation of feed was performed using SBM as substrate, which was sterilized at $121{ }^{\circ} \mathrm{C}$ for $20 \mathrm{~min}$. Prior to fermentation, B. velezensis 157 was cultured for $12 \mathrm{~h}$ in liquid LB medium at $37^{\circ} \mathrm{C}$. L. plantarum BLCC2-0015 was cultured for $16 \mathrm{~h}$ in liquid MRS medium, at $37^{\circ} \mathrm{C}$. The vegetative cells were resuspended in sterile $0.85 \% \mathrm{NaCl}\left(10^{8} \mathrm{CFU} / \mathrm{mL}\right)$ after washed thrice with sterile $0.85 \% \mathrm{NaCl}$.

The sterilized SBM $(150 \mathrm{~g})$ was conducted in a $500 \mathrm{~mL}$ Erlenmeyer flask with a sterile membrane, then sterile water and bacterial suspension in PBS to achieve a final moisture content of $40 \%$ in dry basis. During the first stage of fermentation, SBM was inoculated with $B$. velezensis 157 (8.0 $\log \mathrm{CFU} / \mathrm{g})$ then fermentation was allowed to proceed for $24 \mathrm{~h}$ at $37{ }^{\circ} \mathrm{C}$. For the second stage of fermentation, Erlenmeyer flask was sealed with a sterile rubber plug, the fermented mixture was inoculated with $8.0 \mathrm{log}$ CFU/g of L. plantarum BLCC2-0015 then incubated for $48 \mathrm{~h}$ under anaerobic conditions at $37{ }^{\circ} \mathrm{C}$. The addition of sterile $0.85 \% \mathrm{NaCl}$ instead of inoculated bacteria were served as controls. All control and inoculated samples were tested in triplicate. $2 \mathrm{~g}$ of moist samples at $0 \mathrm{~h}, 24 \mathrm{~h}, 48 \mathrm{~h}$ and $72 \mathrm{~h}$ were collected for immediate determining for $\mathrm{pH}$, microbial, enzyme activity, antimicrobial activity and lactic acid analyses, and the remaining samples were prevented continuous fermentation at $105^{\circ} \mathrm{C}$ for $30 \mathrm{~min}$ (Shi et al. 2017a). Afterwards, all samples were dried for $24 \mathrm{~h}$ at $65^{\circ} \mathrm{C}$, cooled, ground, and subjected to SDS-PAGE, and physicochemical analysis.

\section{Microorganisms and metabolites}

The $\mathrm{pH}$ and microbiological counts were analyzed as described by Jin et al. (2017). A lactic acid enzymology assay kit (Nanjing Jiancheng Technology Co., Ltd.) was used to determine lactic acid content using the manufacturer's protocol provided with the kit. Cellulase, xylanase, pectinase and $\beta$-mannase activities were analyzed by DNS method (Blibech et al. 2020; Parab et al. 2017; Salim et al. 2017). The activity of neutral protease was detected as mentioned by Salim et al. (2017). Antimicrobial activity of FSBM was analyzed using an agar-well diffusion assay. The Staphylococcus aureus ATCC25923 and Escherichia coli ATCC25922 were used as indicator organisms for antimicrobial test (Su et al. 2018). Moist samples after two-stage fermentation were diluted in $0.85 \% \mathrm{NaCl}$ and transferred into a well in the $\mathrm{MH}$ agar containing corresponding pathogens at $37{ }^{\circ} \mathrm{C}$ for $24 \mathrm{~h}$. The control discs were impregnated with supernatant of uninoculated SBM.

\section{Chemical analysis}

Dried samples at $0 \mathrm{~h}, 24 \mathrm{~h}, 48 \mathrm{~h}$, and $72 \mathrm{~h}$ were analyzed according to AOAC International Guidelines (2005) to determine contents of dry matter (DM), crude fibre (CF), crude protein $(\mathrm{CP})$, neutral detergent fiber (NDF), and acid detergent fiber (ADF), total phosphorus (P), Calcium (Ca), ash. The method reported by Ovissipour et al. was used to determine sample TCA-SP content (Ovissipour et al. 2013). An automated amino acid analyzer (LA8080; Hitachi, Tokyo, Japan) was used to determine amino acid profiles. Before analysis, the dried samples were hydrolyzed with $6 \mathrm{~mol} / \mathrm{L} \mathrm{HCl}$ at $110{ }^{\circ} \mathrm{C}$ for $24 \mathrm{~h}$. Analyses of glycinin and $\beta$-conglycinin contents in uninoculated SBM and FSBM were conducted using an indirect competitive enzyme-linked immunosorbent assay (ELISA) kit as per kit instructions (Long zhou fang ke Bio Co., Ltd.).

\section{SDS-PAGE}

A Plant Protein Extraction Kit (Beijing Solarbio Science and Technology Co., Ltd.) was used to extract soluble proteins from uninoculated SBM and FSBM according to the protocol provided. Next, sample protein concentrations were determined using a Bio-Rad Protein Assay Kit (Bio-Rad, USA) and an SDS-PAGE system utilizing $12 \%$ polyacrylamide separating gels for $120 \mathrm{~min}$ at $65 \mathrm{mV}$ to fractionate soluble proteins, as reported by Shi et al. (2017a). Post-electrophoresis, gels were stained for 45 min with Coomassie Brilliant Blue R-250 (Bio-Rad, USA) then destained in 7\% acetic acid.

\section{Microscopic inspection}

Physical property changes of samples were examined by SEM according to the protocol of the Electronic Microscopy Center of Xi'an Lianyi Sharing Information Technology Co. ltd. The microstructures of uninoculated SBM and FSBM were observed using a field-emission SEM (JSM-7900, JEOL, Japan) at $\times 1000, \times 1500, \times 3000$ and $\times 5000$ magnifications.

\section{Statistical analysis}

Data were processed and evaluated by Student's $t$ tests and one-way analysis of variance (ANOVA) with Duncan's multiple-range test using SPSS software (SPSS Inc., Chicago, IL, USA). A P-value ` 0.05 indicated a significant difference between groups, with each result expressed as mean \pm standard deviation. Histograms and line graphs were drawn using GraphPad Prism 8.0 software. 


\section{Results}

\section{Protein degradation capacity}

As shown in Additional file 1: Figure S1 (a and c), $B$. velezensis 157 showed larger hydrolysis diameters on the soybean antigenic protein screening plate, while L. plantarum BLCC2-0015 does not affect.

\section{Microorganisms, $\mathrm{pH}$, antimicrobial activity and lactic acid concentration during SSF}

Two-stage fermentation based on activities of B. velezensis 157 and L. plantarum BLCC2-0015 significantly altered microorganisms, $\mathrm{pH}$ and lactic acid concentration of SBM (Fig. 1a). The initial density of B. velezensis 157 was $8.03 \pm 0.05 \log \mathrm{CFU} / \mathrm{g}$. After $24 \mathrm{~h}$ of incubation, the density increased to $9.93 \pm 0.15 \log C F U / g$. However, the number of $B$. velezensis 157 increase continuously under the second stage of anaerobic fermentation, and the final count was $10.38 \pm 0.29 \log \mathrm{CFU} / \mathrm{g}$ and $11.07 \pm 0.43 \mathrm{log}$ $\mathrm{CFU} / \mathrm{g}$ at $48 \mathrm{~h}$ and $72 \mathrm{~h}$ of incubation. The density of L. plantarum BLCC2-0015 at $24 \mathrm{~h}$ was $8.05 \pm 0.09 \log$ $\mathrm{CFU} / \mathrm{g}$ after inoculation, then the number of $L$. plantarum BLCC2-0015 increased to $10.72 \pm 0.28 \mathrm{log}$ CFU/g and $11.07 \pm 0.33 \log \mathrm{CFU} / \mathrm{g}$ at $48 \mathrm{~h}$ and $72 \mathrm{~h}$ in FSBM, respectively. During the anaerobic fermentation period,
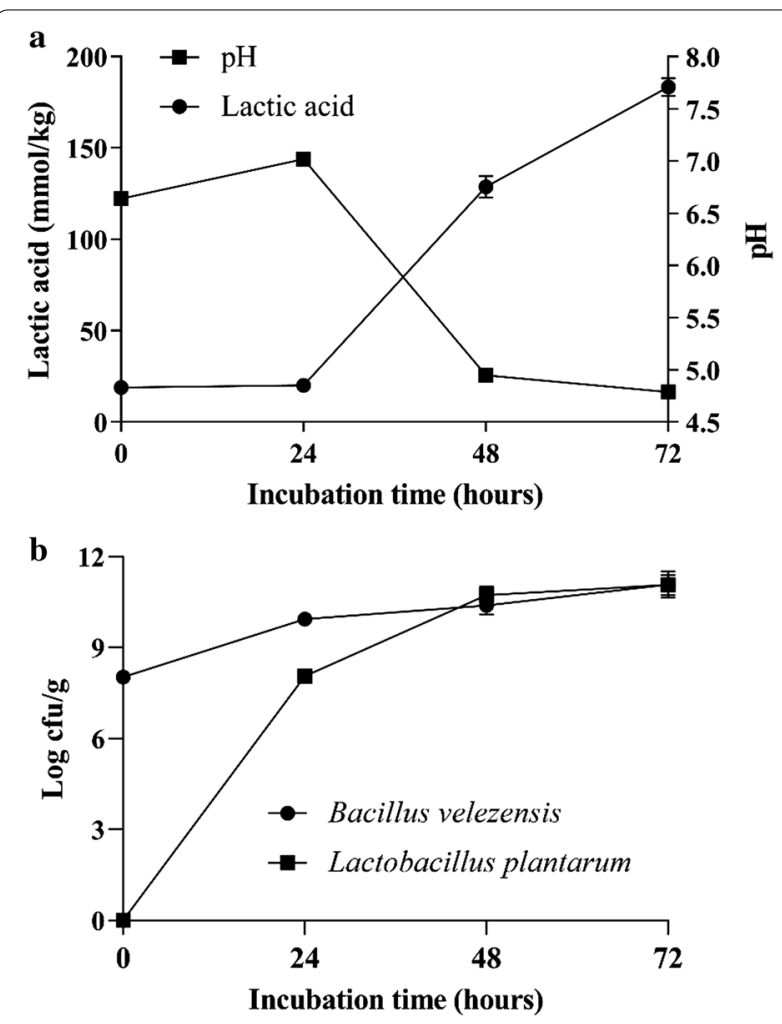

Fig. $1 \mathrm{pH}$, lactic acid concentration $(\mathrm{mmol} / \mathrm{kg})(\mathbf{a})$ and the number of microbial (b) in uninoculated SBM and FSBM during two-stage fermentation the number of L. plantarum BLCC2-0015 was similar to that of B. velezensis 157 (Fig. 1b). During the first stage of fermentation, almost no change in lactic acid content was observed, while a small increase in $\mathrm{pH}$ from $6.64 \pm 0.02$ to $7.02 \pm 0.05$ was observed post-incubation with $B$. velezensis 157. During the second-stage fermentation after L. plantarum BLCC2-0015 inoculated for $48 \mathrm{~h}$, the $\mathrm{pH}$ gradually decreased from $7.02 \pm 0.05$ to $4.78 \pm 0.04$ and was accompanied by a marked increase in lactic acid content from $20.12 \pm 2.31$ to $183.38 \pm 4.86 \mathrm{mmol} /$ kg (Fig. 1a). Besides, FSBM harvested from $24 \mathrm{~h}, 48 \mathrm{~h}$ and $72 \mathrm{~h}$ of two-stage SSF showed antimicrobial activity against $S$. aureus (Additional file 1: Fig. S2 A-C) and E.coli (Additional file 1: Fig. S2 D-F) compared with uninoculated SBM.

\section{Enzymatic activities}

Production of cellulase, xylanase, pectinase, $\beta$-mannanase and neutral protease by two-stage fermentation were tested. Figure $2 \mathrm{e}$ showed that the maximum production of neutral protease was obtained by B. velezensis 157 $(236.94 \pm 10.75 \mathrm{U} / \mathrm{g})$ during the first-stage fermentation, then decreased gradually with the inoculation of L. plantarum BLCC2-0015. Cellulase and xylanase exhibited their maximum activities $22.31 \pm 2.41$ and $44.72 \pm 1.41$ $\mathrm{U} / \mathrm{g}$ at $48 \mathrm{~h}$ and thereafter the enzyme synthesis decrease (Fig. 2a, b). Initially, pectinase and $\beta$-mannanase productions were $14.24 \pm 2.70$ and $17.67 \pm 0.89 \mathrm{U} / \mathrm{g}$ at $24 \mathrm{~h}$ and after that the enzyme activity remained constant. The highest pectinase and $\beta$-mannanase activity were found after $72 \mathrm{~h}$ of two-stage fermentation which were $18.49 \pm 2.52$ and $20.72 \pm 0.69 \mathrm{U} / \mathrm{g}$ (Fig. 2c, d).

\section{Soybean antigenic protein biodegradation after two-stage fermentation}

The SBM yielded separate classic antigenic protein profile bands corresponding to soybean antigenic protein subunits in the range of 20 to $100 \mathrm{kDa}$, including $\beta$-conglycinin peptide subunits $\left(\alpha, \alpha^{\prime}\right.$, and $\left.\beta\right)$ and acidic and basic glycinin peptides normally found in SBM. After $24 \mathrm{~h}$ of fermentation, the antigenic protein of glycinin and $\beta$-conglycinin in FSBM were fractionally degraded into molecules with smaller masses (Fig. 3). Degradation rates of glycinin and $\beta$-conglycinin contents reached $68.14 \%$ and $66.41 \%$, respectively, by $24 \mathrm{~h}$ of $B$. velezensis 157-induced fermentation. Interestingly, a further degree of antigenic protein degradation was observed during second-stage fermentation than during first-stage fermentation. Degradation rates of glycinin and $\beta$-conglycinin contents reached $76.62 \%$ and $71.77 \%$, respectively, by $48 \mathrm{~h}$ of anaerobic fermentation. Respective degradation rates of glycinin and $\beta$-conglycinin contents further increased to $78.60 \%$ and $72.89 \%$ by $72 \mathrm{~h}$ of 

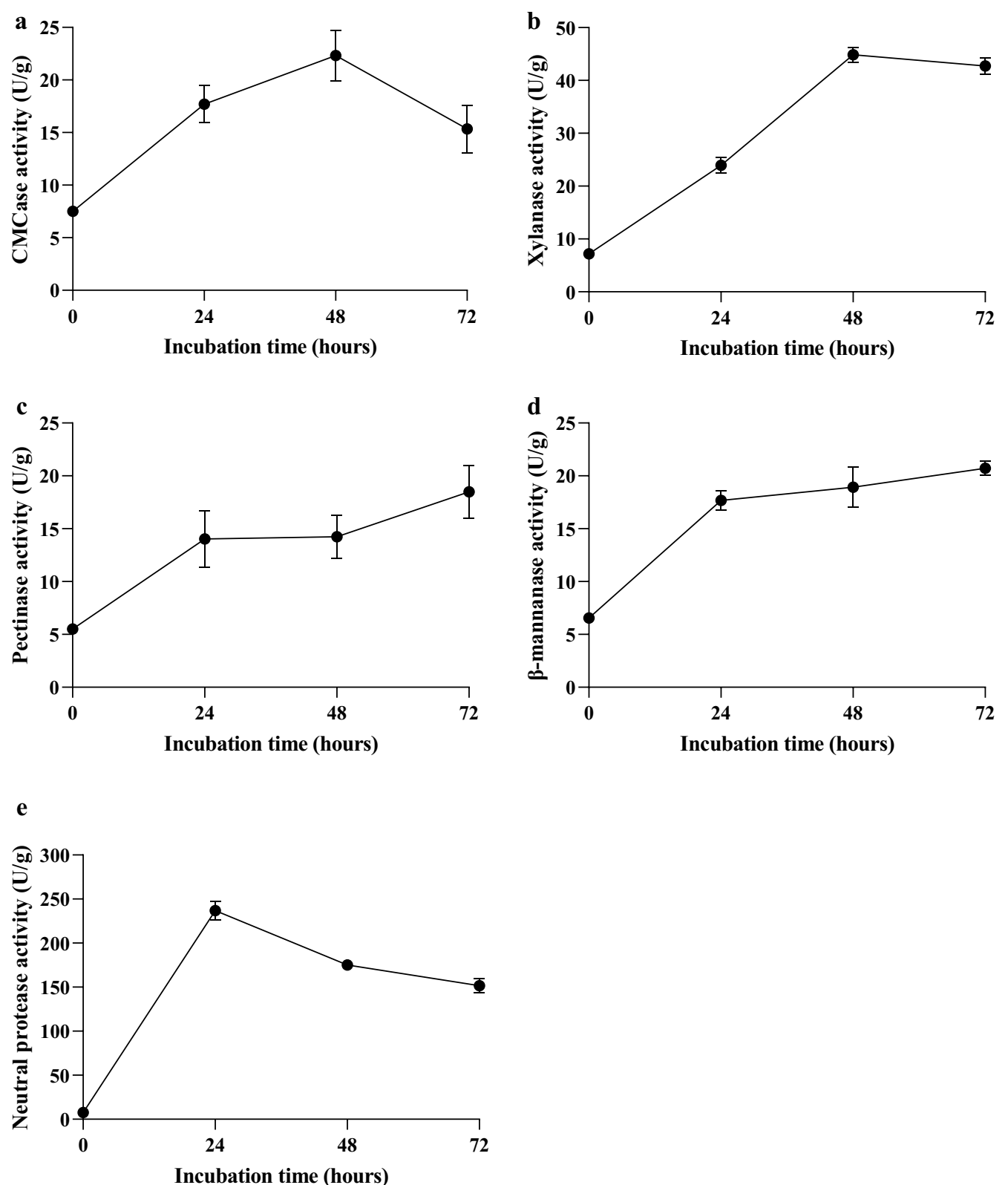

Fig. 2 Production of cellulase (a), xylanase (b), pectinase (c), $\beta$-mannanase (d) and neutral protease (e) of uninoculated SBM and FSBM during two-stage fermentation

anaerobic fermentation, and the difference between the $48 \mathrm{~h}$ and $72 \mathrm{~h}$ of anaerobic fermentation was not significant $(P>0.05)$ (Table 1$)$.

\section{Chemical composition}

The nutrient content characteristics of uninoculated SBM and FSBM samples after two-stage fermentation were presented in Table 2. The crude protein content was $47.28 \pm 0.34 \%$. After $24 \mathrm{~h}$ of fermentation, the crude protein content increased to $51.08 \pm 0.23 \%$ and further reached to $52.36 \pm 0.58 \%$ during $24-48 \mathrm{~h}$ fermentation. Finally, the crude protein content decreased to $51.97 \pm 0.44 \%$ during $48-72 \mathrm{~h}$ fermentation $(P>0.05)$. The TCA-SP content increased significantly from $5.07 \pm 0.06 \%$ to $10.53 \pm 0.10 \%$ was observed in the following $24 \mathrm{~h}$, and gradually increased to $11.58 \pm 0.13 \%$ and $11.79 \pm 0.13 \%$, respectively, during the $24 \mathrm{~h}$ to $48 \mathrm{~h}$ and $48 \mathrm{~h}$ to $72 \mathrm{~h}$ time period. FSBM contained greater concentrations of $\mathrm{Ca}$, ash and total $\mathrm{P}$ than uninoculated SBM. However, 


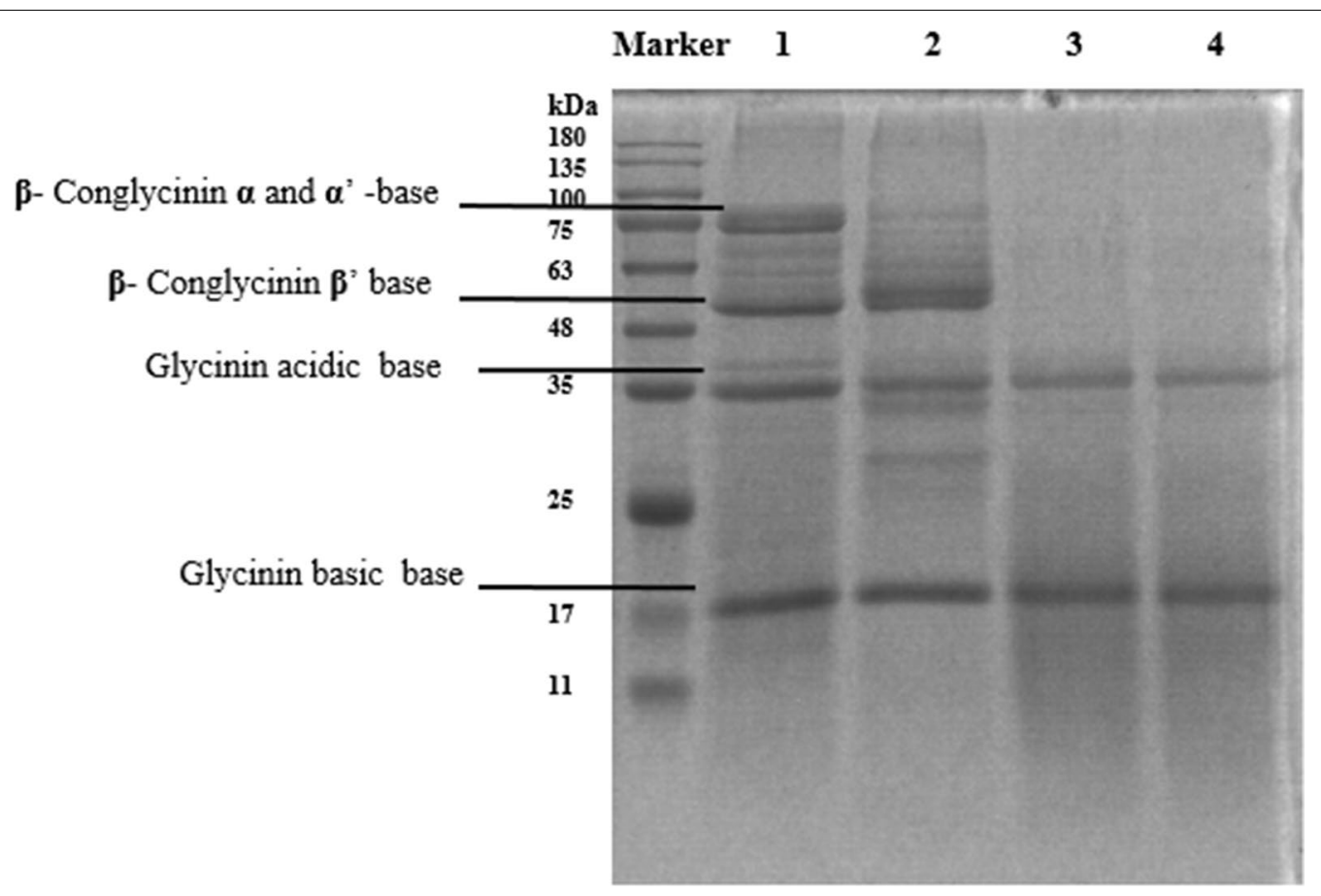

Fig. 3 Effect of degrading glycinin and $\beta$-conglycinin of uninoculated SBM and FSBM during two-stage fermentation. Marker: protein molecular weight markers (11-180 kDa); 1: uninoculated SBM; 2: the SBM was inoculated with B. velezensis 157 and fermented at $37^{\circ} \mathrm{C}$ for $24 \mathrm{~h} ; 3$ : the first-stage fermentation was inoculated with B. velezensis 157 , incubated at $37^{\circ} \mathrm{C}$ for $24 \mathrm{~h}$, then were inoculated with L. plantarum BLCC2-0015 and fermented under anaerobic conditions at $37^{\circ} \mathrm{C}$ for another $24 \mathrm{~h}$; 4:the first-stage fermentation was inoculated with B. velezensis 157 , incubated at $37^{\circ} \mathrm{C}$ for $24 \mathrm{~h}$, then were inoculated with L. plantarum BLCC2-0015 and fermented under anaerobic conditions at $37^{\circ} \mathrm{C}$ for another $48 \mathrm{~h}$

Table 1 Effect of fermentation on the concentration of soybean antigenic protein during two-stage fermentation

\begin{tabular}{|c|c|c|c|c|}
\hline \multirow[t]{2}{*}{ Item } & \multicolumn{2}{|l|}{ Glycinin } & \multicolumn{2}{|l|}{$\beta$-conlycinin } \\
\hline & Content, mg/g & Degradation ${ }^{1}$, \% & Content, mg/g & Degradation, \% \\
\hline SBMO h & $175.14 \pm 4.05^{\mathrm{a}}$ & - & $135.56 \pm 4.10^{\mathrm{a}}$ & - \\
\hline FSBM $24 h^{2}$ & $55.80 \pm 1.89^{b}$ & 68.14 & $45.54 \pm 2.73^{b}$ & 66.41 \\
\hline FSBM $48 \mathrm{~h}^{3}$ & $40.95 \pm 0.79^{c}$ & 76.62 & $38.27 \pm 0.93^{c}$ & 71.77 \\
\hline FSBM $72 \mathrm{~h}^{4}$ & $37.48 \pm 1.31^{c}$ & 78.60 & $36.75 \pm 0.95^{c}$ & 72.89 \\
\hline
\end{tabular}

Values are means of three replicates per treatment. Means in a row without common superscript differ significantly $(P<0.05)$

1 Degradation rate $=$ (soybean antigenic protein content in uninoculated SBM - soybean antigenic protein content in FSBM)/soybean antigenic protein content in uninoculated SBM $\times 100 \%$

2 FSBM $24 \mathrm{~h}$ : the soybean meal was inoculated with B. velezensis 157 and fermented at $37^{\circ} \mathrm{C}$ for $24 \mathrm{~h}$

3 FSBM $48 \mathrm{~h}$ : the first-stage fermentation was inoculated with B. velezensis 157 , incubated at $37^{\circ} \mathrm{C}$ for $24 \mathrm{~h}$, then were inoculated with L. plantarum BLCC2-0015 and fermented under anaerobic conditions at $37^{\circ} \mathrm{C}$ for another $24 \mathrm{~h}$, totally $48 \mathrm{~h}$

4 FSBM $72 \mathrm{~h}$ : the first-stage fermentation was inoculated with B. velezensis 157 , incubated at $37^{\circ} \mathrm{C}$ for $24 \mathrm{~h}$, then were inoculated with L. plantarum BLCC2-0015 and fermented under anaerobic conditions at $37^{\circ} \mathrm{C}$ for another $48 \mathrm{~h}$, totally $72 \mathrm{~h}$

the content of the samples increased during the $0 \mathrm{~h}$ to 48 -h time period, and decreased following the 48-72 h. The hemicellulose content decreased significantly from $19.90 \pm 0.14 \%$ to $14.33 \pm 0.09 \%$ during the first-stage processes. The relative cellulose and hemicellulose degradation rate of uninoculated SBM were significantly reduced by $22.10 \%$ and $39.15 \%$ observed during two-stage fermentation, respectively. Notably, inoculation with both B. velezensis 157 and L. plantarum BLCC2-0015 markedly altered AA composition profiles of uninoculated SBM. All the AA content increased during the $0-24 \mathrm{~h}$ period time, then the AA content showed marginal enrichment during the second stage fermentation. Correspondingly, the difference of AA content between the $24 \mathrm{~h}, 48 \mathrm{~h}$ and $72 \mathrm{~h}$ of fermentation was not significant $(P>0.05)$. Ultimately, 
Table 2 Analyzed nutrient composition of uninoculated SBM and FSBM during two-stage fermentation

\begin{tabular}{|c|c|c|c|c|}
\hline $\begin{array}{l}\text { Item } \\
(\%)\end{array}$ & SBM Oh & FSBM $24 h^{1}$ & FSBM $48 h^{2}$ & FSBM $72 h^{3}$ \\
\hline M & $93.35 \pm 0.46^{a}$ & $92.79 \pm 0.42^{\mathrm{ab}}$ & $91.84 \pm 0.96^{b c}$ & $90.88 \pm 0.66^{c}$ \\
\hline $\mathrm{CP}$ & $47.28 \pm 0.34^{c}$ & $51.08 \pm 0.23^{b}$ & $52.36 \pm 0.58^{\mathrm{a}}$ & $51.97 \pm 0.44^{\mathrm{a}}$ \\
\hline CA-SP & $5.07 \pm 0.06^{d}$ & $10.53 \pm 0.10^{c}$ & $11.58 \pm 0.13^{b}$ & $11.79 \pm 0.13^{\mathrm{a}}$ \\
\hline $\begin{array}{c}\text { Crude } \\
\text { fibre }\end{array}$ & $5.29 \pm 0.08^{b}$ & $5.72 \pm 0.08^{\mathrm{a}}$ & $5.40 \pm 0.07^{b}$ & $5.14 \pm 0.05^{c}$ \\
\hline $\begin{array}{l}\text { Cellu- } \\
\text { lose }^{3}\end{array}$ & & & & \\
\hline $\begin{array}{l}\text { Hemi- } \\
\text { cellu- } \\
\text { lose }^{4}\end{array}$ & $19.90 \pm 0.14^{\mathrm{a}}$ & $33 \pm 0.09^{b}$ & $12.59 \pm 0.22^{c}$ & $12.11 \pm 0.15^{d}$ \\
\hline Ash & $6.16 \pm 0.06^{d}$ & $6.58 \pm 0.07^{\mathrm{a}}$ & $6.38 \pm 0.06^{b}$ & $6.27 \pm 0.03^{c}$ \\
\hline $\mathrm{Ca}$ & $0.33 \pm 0.01^{c}$ & $0.35 \pm 0.01^{\mathrm{ab}}$ & $0.36 \pm 0.01^{\mathrm{a}}$ & $0.34 \pm 0.01^{b c}$ \\
\hline Total P & $0.61 \pm 0.01^{c}$ & $0.71 \pm 0.01^{\mathrm{a}}$ & $0.70 \pm 0.01^{\mathrm{a}}$ & $0.69 \pm 0.01^{b}$ \\
\hline \multicolumn{5}{|c|}{ Indispensable AA } \\
\hline Arg & $3.18 \pm 0.04$ & $3.25 \pm 0.01$ & $3.40 \pm 0.23$ & $3.37 \pm 0.13$ \\
\hline His & $1.09 \pm 0$ & $1.25 \pm 0.01^{\mathrm{a}}$ & $1.25 \pm 0.09^{a}$ & $1.26 \pm 0.06^{\mathrm{a}}$ \\
\hline Ile & & & & \\
\hline Leu & $3.62 \pm 0.04$ & $4.03 \pm 0.03$ & $3.95 \pm 0.29$ & $3.95 \pm 0.19$ \\
\hline Lys & $2.54 \pm 0.02$ & $2.78 \pm 0.01$ & $2.72 \pm 0.18$ & $2.72 \pm 0.13$ \\
\hline Met & $0.265 \pm 0.01$ & $0.32 \pm 0.03$ & $0.35 \pm 0.04$ & $0.31 \pm 0.04$ \\
\hline Phe & $2.09 \pm 0.02$ & $2.42 \pm 0.02$ & $2.36 \pm 0.23$ & $2.39 \pm 0.11$ \\
\hline Thr & $1.76 \pm 0.03^{b}$ & $2.00 \pm 0.01^{\mathrm{a}}$ & $2.01 \pm 0.06^{\mathrm{a}}$ & $2.01 \pm 0.01^{\mathrm{a}}$ \\
\hline Val & $2.14 \pm 0.07$ & & & $.36 \pm 0.11$ \\
\hline \multicolumn{5}{|c|}{ Dispensable AA } \\
\hline Asp & $5.14 \pm 0.01^{b}$ & $5.69 \pm 0.03^{\mathrm{a}}$ & $5.59 \pm 0.35^{\mathrm{ab}}$ & $5.72 \pm 0.07^{\mathrm{a}}$ \\
\hline Ser & $2.17 \pm 0.02^{b}$ & $2.45 \pm 0.01^{\mathrm{a}}$ & $2.40 \pm 0.16^{\mathrm{ab}}$ & $2.39 \pm 0.09^{a b}$ \\
\hline Glu & $7.89 \pm 0.01^{b}$ & $9.53 \pm 0.06^{\mathrm{a}}$ & $9.07 \pm 0.56^{\mathrm{a}}$ & $9.05 \pm 0.33^{\mathrm{a}}$ \\
\hline Gly & $1.94 \pm 0.04^{b}$ & $2.19 \pm 0.01^{\mathrm{a}}$ & $2.16 \pm 0.14^{\mathrm{a}}$ & $2.22 \pm 0.01^{\mathrm{a}}$ \\
\hline Ala & $1.98 \pm 0.04$ & $2.23 \pm 0.02$ & $2.22 \pm 0.16$ & $2.24 \pm 0.10$ \\
\hline Cys & $0.41 \pm 0.01^{b}$ & $0.53 \pm 0.01^{\mathrm{a}}$ & $0.49 \pm 0.06^{\mathrm{ab}}$ & $0.50 \pm 0.06^{\mathrm{ab}}$ \\
\hline Tyr & $1.21 \pm 0.02^{b}$ & $1.38 \pm 0.01^{\mathrm{ab}}$ & $1.40 \pm 0.13^{\mathrm{ab}}$ & $1.42 \pm 0.07^{\mathrm{a}}$ \\
\hline Pro & $2.33 \pm 0.03^{b}$ & $2.47 \pm 0.02^{\mathrm{ab}}$ & $2.54 \pm 0.24^{\mathrm{ab}}$ & $2.69 \pm 0.01^{\mathrm{a}}$ \\
\hline $\begin{array}{r}\text { Total } \\
\text { AA }\end{array}$ & $41.72 \pm 0.40^{b}$ & $47.14 \pm 0.14^{\mathrm{a}}$ & $46.47 \pm 3.20^{\mathrm{ab}}$ & $46.77 \pm 1.67^{\mathrm{ab}}$ \\
\hline
\end{tabular}

Values are means of three replicates per treatment. Means in a row without common superscript differ significantly $(P<0.05)$

1 FSBM 24 h: the soybean meal was inoculated with B. velezensis 157 and fermented at $37^{\circ} \mathrm{C}$ for $24 \mathrm{~h}$

2 FSBM 48 h: the first-stage fermentation was inoculated with B. velezensis 157 , incubated at $37^{\circ} \mathrm{C}$ for $24 \mathrm{~h}$, then were inoculated with L. plantarum BLCC2-0015 and fermented under anaerobic conditions at $37^{\circ} \mathrm{C}$ for another $24 \mathrm{~h}$

3 FSBM $72 \mathrm{~h}$ : the first-stage fermentation was inoculated with B. velezensis 157 , incubated at $37^{\circ} \mathrm{C}$ for $24 \mathrm{~h}$, then were inoculated with L. plantarum BLCC2-0015 and fermented under anaerobic conditions at $37^{\circ} \mathrm{C}$ for another $48 \mathrm{~h}$

${ }^{4}$ Cellulose $=$ ADF - residue after $72 \%$ sulfuric acid treatment

5 Hemicellulose $=$ NDF - ADF

as compared to uninoculated SBM, the total AA content of first-stage fermented feed markedly increased from $41.72 \pm 0.40 \%$ to $47.14 \pm 0.14 \%$, which increased by 1.13 times. Additionally, no significant difference in AA content was observed between first-stage and twostage fermentation.

\section{Microscopic observation}

The physical structures of uninoculated SBM and FSBM during two-stage fermentation were investigated by SEM. Figure 4 shows the surface images of uninoculated SBM at magnification of $\times 1000, \times 1500, \times 3000$ and $\times 5000$, with compact and smooth-faced structures. After twostage fermentation, FSBM showed fragmental, cracked and plurilocellate structures.

\section{Discussion}

Soybean meal production is widespread and abundant, prompting efforts to utilize SBM as an important plant protein resource in animal feed. However, SBM contains several ANFs that limit its extensive use in the diet of young animals (Wongputtisin et al. 2012). Fortunately, several studies have shown that microbial fermentation can degrade, and thus remove, antigenic proteins from SBM to improve its nutritional characteristics (Medeiros et al. 2018; Zheng et al. 2017; Zhu et al. 2017). In this work, a novel two-stage solid-state fermentative system for SBM processing was used to alter the fermentation quality. The contents of glycinin and $\beta$-conglycinin in FSBM were degraded by $68.14 \%$ and $66.41 \%$ during the first fermentation. B. velezensis 157 was screened and verified to degrade soybean antigenic protein on a specific screening plate. Meanwhile, many genes encoding proteolytic enzymes of $B$. velezensis 157 , such as serine proteases, aminopeptidases, and metalloproteases, were detected in the genome of this strain (Chen et al. 2018b). Correspondingly, the enzyme activity of neutral protease was significantly increased during $B$. velezensis 157 fermentation. Therefore, the hydrolytic effects of the proteases secreted by $B$. velezensis 157 were able to decompose antigenic protein in FSBM during the first fermentation. Aligning with previous results obtained by Shi et al. demonstrating that inoculation of cornsoybean meal mixed feed with B.subtilis and E.faecium led to degradation of ANFs and enhanced nutritional value. In that study, ELISA analysis revealed glycinin and $\beta$-conglycinin degradation rates of $86.12 \%$ and $77.53 \%$, respectively, although no soybean antigenic protein degradation occurred during the second fermentative stage (Shi et al. 2017a). Interestingly, in the present study ANFs degradation did occur during the second stage of fermentation, the respective degradation rates of glycinin and $\beta$-conglycinin contents further increased to $76.62 \%$ and $71.77 \%$ during the $48 \mathrm{~h}$ fermentation. As the raw materials have been sterilized before fermentation, and the fermentation process is also sterile. No effects of 


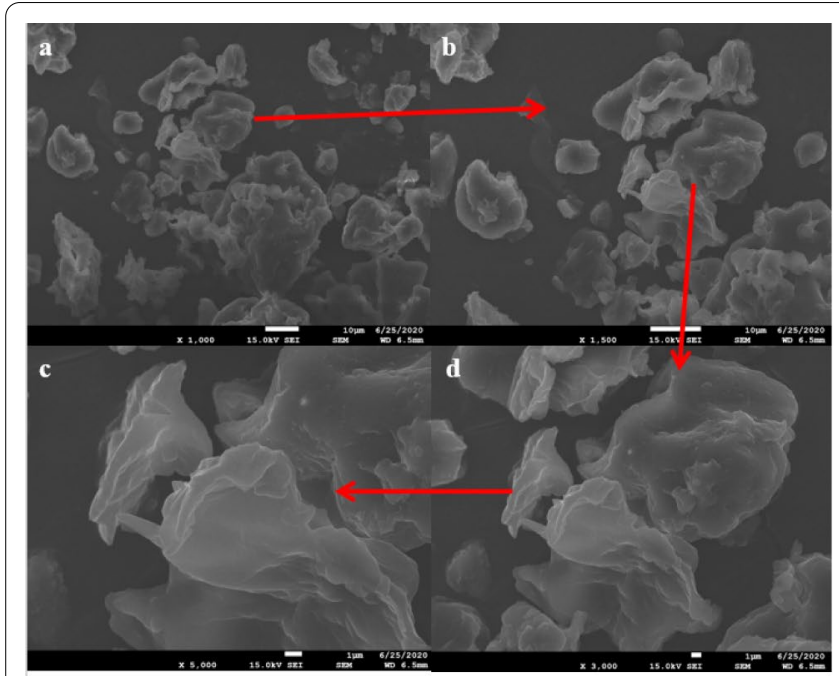

Uninoculated SBM (A)

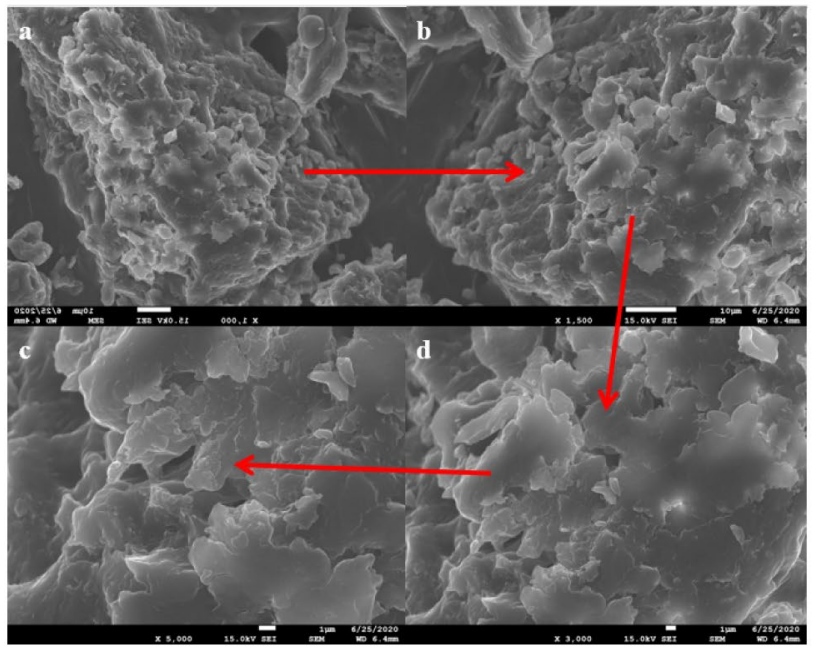

FSBM 24h (B)

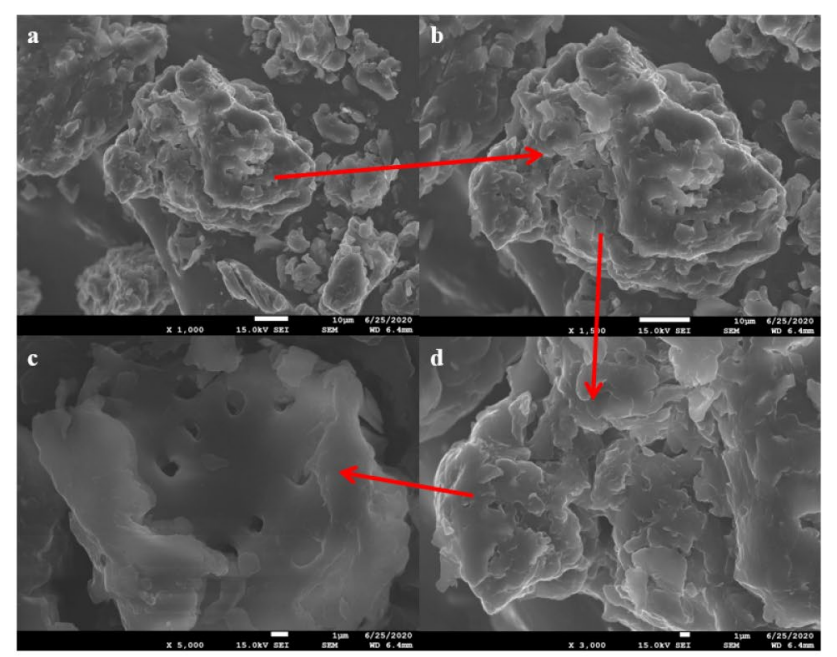

FSBM 48h (C)

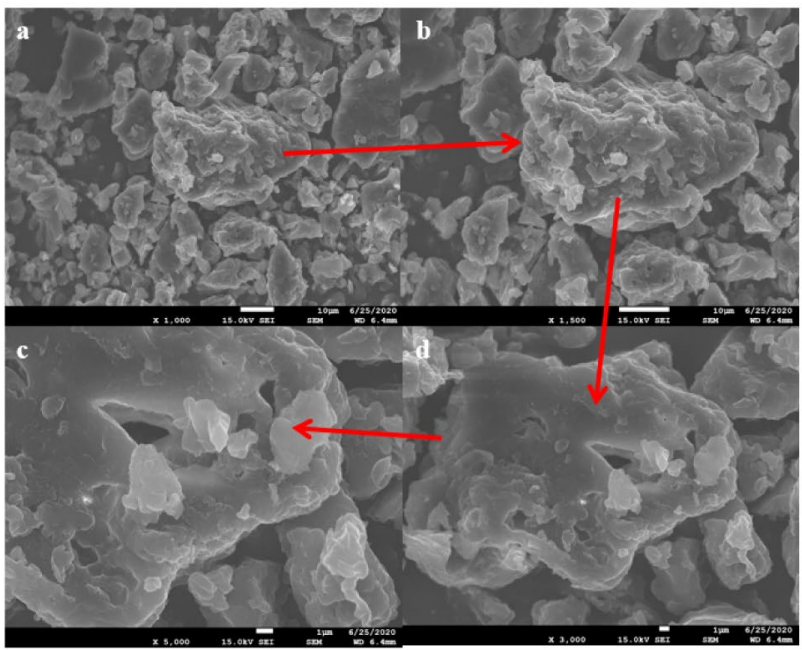

FSBM 72h (D)

Fig. 4 SEM image of uninoculated SBM and FSBM during two-stage fermentation. a Uninoculated SBM; $\mathbf{b}$ the SBM was inoculated with B. velezensis 157 and fermented at $37^{\circ} \mathrm{C}$ for $24 \mathrm{~h}$; $\mathbf{c}$ the first-stage fermentation was inoculated with B. velezensis 157 , incubated at $37^{\circ} \mathrm{C}$ for $24 \mathrm{~h}$, then were inoculated with L. plantarum BLCC2-0015 and fermented under anaerobic conditions at $37^{\circ} \mathrm{C}$ for another $24 \mathrm{~h}$; $\mathbf{d}$ the first-stage fermentation was inoculated with B. velezensis 157 , incubated at $37^{\circ} \mathrm{C}$ for $24 \mathrm{~h}$, then were inoculated with L. plantarum BLCC2-0015 and fermented under anaerobic conditions at $37^{\circ} \mathrm{C}$ for another $48 \mathrm{~h}$. All the images were at 1000 (a), 1500 (b), 3000 (c) and 5000 (d) fold magnification

exogenous microorganisms or natural microorganisms present during fermentation are involved. Therefore, $B$. velezensis 157 may still maintain a vital role in the second fermentation, which continues to ferment using residual oxygen in the culture environment. Notably, the results of microbiological counts in this study revealed that $B$. velezensis 157 exhibited the greatest abundance during anaerobic fermentation. Although L. plantarum BLCC20015 could not degrade soybean antigenic protein as shown in Additional file 1: Figure S1(c), perhaps low $\mathrm{pH}$ and structural changes caused by L. plantarum BLCC20015 may affect the degradation effect of B. velezensis 157 as the prolonged fermentation duration. Thus, the content of glycinin and $\beta$-conglycinin on FSBM was not further degraded during the process of $72 \mathrm{~h}$ fermentation. The protein profile obtained by SDS-PAGE was in accord with the degradation trends of glycinin and $\beta$-conglycinin by ELISA analysis during the two-stage fermentation. Moreover, further research is needed to identify the proteins in the fermented products by $2 \mathrm{DE}$ and proteomics analysis.

Nevertheless, in this work, FSBM contained greater concentrations of $\mathrm{CP}$ and AA content than did uninoculated SBM, with significant differences in amino acid 
composition after B. velezensis 157 treatment, which is consistent with previous experimental research on FSBM (Feng et al. 2007; Frias et al. 2008). It was consistent with reports that the loss of DM may cause the increase of CP and AA during fermentation (Shi et al. 2017b). However, the CP content of FSBM during second-stage fermentation with L. plantarum BLCC2-0015 was not changed much. This may be attributed to L. plantarum may convert carbohydrate into organic acid. Meanwhile, first-stage fermentation with $B$. velezensis 157 led to an increased TCA-SP level $(10.53 \pm 0.10 \%)$ as compared to the corresponding level in uninoculated SBM, with a slowly increasing observed for second-stage fermentation by $L$. plantarum BLCC2-0015 $(11.79 \pm 0.125 \%$ for fermented SBM vs. $5.07 \pm 0.057 \%$ for uninoculated SBM). This result is mainly due to hydrolysis of antigenic proteins to form small molecular peptides and free amino acids during fermentation (Gilbert et al. 2008). As an alternative explanation, the increase of TCA-SP might also be due to the hydrolysis of other SBM proteins during two-stage fermentation. During second-stage fermentation, after L. plantarum BLCC2-0015 inoculation the $\mathrm{pH}$ gradually decreased from $7.02 \pm 0.05$ to $4.78 \pm 0.04$, and the lactic acid production was linearly increased. As several previously published studies fermented product with bacterial metabolites, such as acidic substances or bacteriocins, may inhibit proliferation of pathogens (e.g. Enterobacteriaceae) (Wang et al. 2015). In this study, FSBM had an antimicrobial effect on the growth of $S$. aureus and $E$. coli in vitro. It had been demonstrated that $B$. velezensis 157 antibacterial effect against a broad spectrum of food-borne pathogens in our previous study (Chen et al. 2018b). Additionally, the high LA content and low $\mathrm{pH}$ of FSBM during second fermentation are essential for pathogen inhibition (Zhu et al. 2017). Thus, The FSBM showed potential for compensate the use of antibiotics in feed.

In the present study, levels of hemicellulose and cellulose in uninoculated SBM declined by $27.99 \%$ and $19.81 \%$, respectively, and were most significantly altered during first-stage fermentation in the presence of $B$. velezensis 157, after which hemicellulose levels continued to decrease, reaching a lower level of $39.15 \%$ during second-stage fermentation. Moreover, several NSP-degrading enzymes activities (NSPases, cellulase, xylanase, $\beta$-mannanase, and pectinase) were determined from the fermented product during the twostage fermentation, which may cause the breakdown of antinutritional substrates above. Additionally, With the degradation of cellulose and hemicellulose, the protein would be degraded easily by protease of B. velezensis 157. Correspondingly, it was observed by SEM that the surface structure of FSBM showed cracked and porous structure compared with uninoculated SBM after fermentation. This indicated that the lignocellulose component of SBM may be degraded and such changes of surface structure in FSBM may drive by NSPases and protease secreted during the process. Therefore, lower cellulose and hemicellulose indicated that FSBM may have higher nutrient digestibility than the uninoculated SBM. Furthermore, comparative genome analysis of $B$. velezensis has detected genes encoding common lignocellulolytic enzymes that could effectively degrade cellulose and hemicellulose, but failed to identify a cellobiohydrolase that could directly hydrolyze cellulose (Chen et al. 2018a), explaining the limited cellulose degradation rate observed here during two-stage fermentation. By contrast, the hemicellulose degradation rate approached 39\% during two-stage fermentation, a result likely since $B$. velezensis 157 is equipped with numerous hemicellulose-degrading enzymes, such as $1,4-\beta$-xylosidase, endo-1,4- $\beta$-xylanase, arabinan endo1,5- $\alpha$ - $\mathrm{L}$-arabinosidase, $\alpha-N$-arabinofuranosidase, arabinoxylan arabinofuranohydrolase, $\beta$-mannosidase, arabinogalactan endo-1,4- $\beta$-galactosidase, and glucuronoxylanase. Moreover, carbohydrate esterases, pectate lyase, and carbohydrate-binding modules (CBMs) that are known to be produced by $B$. velezensis 157 may also influence cellulose and hemicellulose degradation. However, to date few published reports have described the effects of these novel lignocellulolytic enzymes on lignocellulose biodegradation aside from enzymes produced by B. velezensis strains ZY-1-1 (Zhang et al. 2018) and ASN1 (Nair et al. 2018). Notably, recent wholegenome analysis reports of $B$. velezensis strains GH1-13 (Kim et al. 2017), FZB42 (Fan et al. 2018), UCMB5113 (Niazi et al. 2014), and LS69 (Liu et al. 2017) predict a series of lignocellulose -degrading enzyme genes that may play a role in bacterial colonization of plant roots. Nevertheless, little research has been published describing B. velezensis as an animal feed probiotic, prompting us to optimize its use in fermentation to remove ANFs from SBM for livestock feed use.

In summary, during two-stage SBM fermentation induced by stepwise inoculation of B. velezensis 157 followed by $L$. plantarum BLCC2-0015. The results indicated that $B$. velezensis 157 could significantly alter the nutritional characteristics of uninoculated SBM based on degrading ANFs (soybean antigenic protein, cellulose, and hemicellulose), changing physicochemical features and functional metabolites, while L. plantarum BLCC20015 mainly functioned to reduce $\mathrm{pH}$ and generate high lactic acid concentration for pathogen inhibition and feed preservation. Therefore, B. velezensis 157 holds great promise as an animal feed additive that enhances agricultural products' value. 


\section{Supplementary information}

The online version contains supplementary material available at https://doi. org/10.1186/s13568-021-01184-x.

Additional file 1: Figure S1. Protein degradation capacity of B. velezensis 157 and L. plantarum BLCC2-0015. Figure S2. Antimicrobial activity of the fermented product

\section{Acknowledgements}

This research was supported by The 68th general grant of China Postdoctoral Science Foundation (project no. 2020M681063);Agricultural Science and Technology Innovation Project of Jilin Province (project no. C02104206); Agricultural Science and Technology Innovation Project of Jilin Province (project no. C02104207); Funding program for High-level scientific and technological innovation talents introduced by Scientific research Institutes of Jilin Province (project no. 2018001); Local standard project of Jilin Province ((project no.DBXM045-2020).

\section{Authors' contributions}

LC conceived the study; LC, ZZ, WG, HX, BW, and XY implemented the methodology; ZZ, WY, LZ. BW, JL and XY analyzed the results; LC and ZZ wrote the manuscript. All authors read and approved the final manuscript.

\section{Ethics approval and consent to participate}

This article does not contain any studies with human participants or animals performed by any of the authors.

\section{Competing interests}

The authors declare that they have no conflict of interest.

\section{Author details}

${ }^{1}$ Institute of Animal Nutrition and Feed, Jilin Academy of Agricultural Sciences, No. 186 Dong Xinghua Street, Gongzhuling 136100, Jilin, China. ${ }^{2}$ Institute of Agro-food Technology, Jilin Academy of Agricultural Sciences, Changchun 130033, China. ${ }^{3}$ Shandong BaoLai-LeeLai Bioengineering Co. Ltd., Tai'an 271000, Shandong, People's Republic of China.

Received: 30 December 2020 Accepted: 23 January 2021

Published online: 05 February 2021

\section{References}

Adeniji AA, Loots DT, Babalola OO (2019) Bacillus velezensis: phylogeny, useful applications, and avenues for exploitation. Appl Microbiol Biotechnol 103(9):3669-3682. https://doi.org/10.1007/s00253-019-09710-5

Blibech M, Farhat-Khemakhem A, Kriaa M, Aslouj R, Boukhris I, Alghamdi O, Chouayekh H (2020) Optimization of $\beta$-mannanase production by Bacillus subtilis US191 using economical agricultural substrates. Biotechnol Prog 36(4):e2989. https://doi.org/10.1002/btpr.2989

Chen K, Kho W, You S, Yeh R, Tang S, Hsieh C (2009) Effects of Bacillus subtilis var. natto and Saccharomyces cerevisiae mixed fermented feed on the enhanced growth performance of broilers. Poult Sci 88(2):309-315. https ://doi.org/10.3382/ps.2008-00224

Chen L, Gu W, Xu HY, Yang GL, Shan XF, Chen G, Kang YH, Wang CF, Qian AD (2018a) Comparative genome analysis of Bacillus velezensis reveals a potential for degrading lignocellulosic biomass. 3 Biotech 8(5):253. https ://doi.org/10.1007/s13205-018-1270-7

Chen L, Gu W, Xu HY, Yang GL, Shan XF, Chen G, Wang CF, Qian AD (2018b) Complete genome sequence of Bacillus velezensis 157 isolated from Eucommia ulmoides with pathogenic bacteria inhibiting and lignocellulolytic enzymes production by SSF. 3 Biotech 8(2):114. https://doi. org/10.1007/s13205-018-1125-2

Chen L, Heng J, Qin S, Bian K (2018c) A comprehensive understanding of the biocontrol potential of Bacillus velezensis LM2303 against Fusarium head blight. PLoS ONE 13(6):e0198560. https://doi.org/10.1371/journ al.pone.0198560
Dunlap CA, Kim SJ, Kwon SW, Rooney AP (2016) Bacillus velezensis is not a later heterotypic synonym of Bacillus amyloliquefaciens; Bacillus methylotrophicus, Bacillus amyloliquefaciens subsp. plantarum and 'Bacillus oryzicola' are later heterotypic synonyms of Bacillus velezensis based on phylogenomics. Int J Syst Evol Microbiol 66(3):1212-1217. https://doi.org/10.1099/ ijsem.0.000858

Fan B, Blom J, Klenk HP, Borriss R (2017) Bacillus amyloliquefaciens, Bacillus velezensis, and Bacillus siamensis form an "Operational Group B. amyloliquefaciens" within the B. subtilis species complex. Frontiers in microbiology 8:22. https://doi.org/10.3389/fmicb.2017.00022

Fan B, Wang C, Song X, Ding X, Wu L, Wu H, Gao X, Borriss R (2018) Bacillus velezensis FZB42 in 2018: the gram-positive model strain for plant growth promotion and biocontrol. Front Microbiol 9:2491. https://doi. org/10.3389/fmicb.2018.02491

Feng J, Liu X, Xu Z, Lu Y, Liu Y (2007) Effect of fermented soybean meal on intestinal morphology and digestive enzyme activities in weaned piglets. Dig Dis Sci 52(8):1845-1850. https://doi.org/10.1007/s10620-006-9705-0

Frias J, Song YS, Martínez-Villaluenga C, González de Mejia E, Vidal-Valverde C (2008) Immunoreactivity and amino acid content of fermented soybean products. J Agric Food Chem 56(1):99-105. https://doi.org/10.1021/jf072 $177 \mathrm{j}$

Gilbert E, Wong E, Webb K (2008) Board-invited review: peptide absorption and utilization: Implications for animal nutrition and health. J Anim Sci 86(9):2135-2155. https://doi.org/10.2527/jas.2007-0826

Hong K, Lee C, Kim S (2004) Aspergillus oryzae GB-107 fermentation improves nutritional quality of food soybeans and feed soybean meals. J Med Food 7(4):430-435. https://doi.org/10.1089/jmf.2004.7.430

Jin W, Ye H, Jin-Zhao Z, Zhi-Jiang Z, Huan F (2017) Consuming fermented distillers' dried grains with solubles (DDGS) feed reveals a shift in the faecal microbiota of growing and fattening pigs using 454 pyrosequencing. J Integr Agric 16(4):900-910. https://doi.org/10.1016/S2095-3119(16)61523 $-X$

Kim SY, Song H, Sang MK, Weon HY, Song J (2017) The complete genome sequence of Bacillus velezensis strain $\mathrm{GH} 1-13$ reveals agriculturally beneficial properties and a unique plasmid. J Biotechnol 259:221-227. https:// doi.org/10.1016/j.jbiotec.2017.06.1206

Koutsoumanis K, Allende A, Alvarez-Ordóñez A, Bolton D, Bover-Cid S, Chemaly M, Davies R, De Cesare A, Hilbert F, Lindqvist R, Nauta M, Peixe $L, R u$ G, Simmons M, Skandamis P, Suffredini E, Cocconcelli P, Fernández Escámez P, Maradona M, Querol A, Suarez J, Sundh I, Vlak J, Barizzone F, Correia S, Herman L (2020a) Scientific opinion on the update of the list of QPS-recommended biological agents intentionally added to food or feed as notified to EFSA (2017-2019). EFSA J Eur Food Saf Auth 18(2):e05966. https://doi.org/10.2903/j.efsa.2020.5966

Koutsoumanis K, Allende A, Alvarez-Ordóñez A, Bolton D, Bover-Cid S, Chemaly M, Davies R, De Cesare A, Hilbert F, Lindqvist R, Nauta M, Peixe L, Ru G, Simmons M, Skandamis P, Suffredini E, Cocconcelli P, Fernández Escámez P, Maradona M, Querol A, Suarez J, Sundh I, Vlak J, Barizzone F, Hempen M, Herman L (2020b) Update of the list of QPS-recommended biological agents intentionally added to food or feed as notified to EFSA 12: suitability of taxonomic units notified to EFSA until March 2020. EFSA J Eur Food Saf Auth 18(7):e06174. https://doi.org/10.2903/j.efsa.2020.6174

Liu C, Wang H, Cui Z, He X, Wang X, Zeng X, Ma H (2007) Optimization of extraction and isolation for 115 and 75 globulins of soybean seed storage protein. Food Chem 102(4):1310-1316. https://doi.org/10.1016/j.foodc hem.2006.07.017

Liu G, Kong Y, Fan Y, Geng C, Peng D, Sun M (2017) Whole-genome sequencing of Bacillus velezensis LS69, a strain with a broad inhibitory spectrum against pathogenic bacteria. J Biotechnol 249:20-24. https://doi. org/10.1016/j.jbiotec.2017.03.018

Maruyama N, Sato R, Wada Y, Matsumura Y, Goto H, Okuda E, Nakagawa S, Utsumi S (2000) Structure-physicochemical function relationships of soybean beta-conglycinin constituent subunits. J Agric Food Chem 48(2):576. https://doi.org/10.1021/jf0000023

Medeiros S, Xie J, Dyce PW, Cai HY, DeLange K, Zhang H, Li J (2018) Isolation of bacteria from fermented food and grass carp intestine and their efficiencies in improving nutrient value of soybean meal in solid state fermentation. J Anim Sci Biotechnol 9:29. https://doi.org/10.1186/s4010 4-018-0245-1

Nair A, Al-Battashi H, Al-Akzawi A, Annamalai N, Gujarathi A, Al-Bahry S, Dhillon G, Sivakumar N (2018) Waste office paper: a potential feedstock 
for cellulase production by a novel strain Bacillus velezensis ASN1. Waste Manage 79:491-500. https://doi.org/10.1016/j.wasman.2018.08.014

Niazi A, Manzoor S, Asari S, Bejai S, Meijer J, Bongcam-Rudloff E (2014) Genome analysis of Bacillus amyloliquefaciens subsp. plantarum UCMB5113: a rhizobacterium that improves plant growth and stress management. PLoS ONE 9(8):e104651. https://doi.org/10.1371/journal.pone.0104651

Ovissipour M, Abedian A, Motamedzadegan A, Rasco B, Safari R, Shahiri H (2013) The effect of enzymatic hydrolysis time and temperature on the properties of protein hydrolysates from Persian sturgeon (Acipenser persicus) viscera. Food Chem 115(1):238-242. https://doi.org/10.1016/j. foodchem.2008.12.013

Pan HQ, Li QL, Hu JC (2017) The complete genome sequence of Bacillus velezensis $9912 \mathrm{D}$ reveals its biocontrol mechanism as a novel commercial biological fungicide agent. J Biotechnol 247:25-28. https://doi. org/10.1016/j.jbiotec.2017.02.022

Parab P, Khandeparker R, Amberkar U, Khodse V (2017) Bacillus enzymatic saccharification of seaweeds into fermentable sugars by xylanase from marine sp strain BT21. Biotech 7(5):296. https://doi.org/10.1007/s1320 5-017-0921-4

Salim A, Grbavčić S, Šekuljica N, Stefanović A, Jakovetić Tanasković S, Luković N, Knežević-Jugović Z (2017) Production of enzymes by a newly isolated Bacillus sp. TMF-1 in solid state fermentation on agricultural by-products: the evaluation of substrate pretreatment methods. Biores Technol 228:193-200. https://doi.org/10.1016/j.biortech.2016.12.081

Shi C, Zhang Y, Lu Z, Wang Y (2017a) Bacillus subtilis Solid-state fermentation of corn-soybean meal mixed feed with and for degrading antinutritional factors and enhancing nutritional value. J Anim Sci Biotechnol 8:50. https ://doi.org/10.1186/s40104-017-0184-2

Shi C, Zhang Y, Yin Y, Wang C, Lu Z, Wang F, Feng J, Wang Y (2017b) Bacillus subtilis amino acid and phosphorus digestibility of fermented corn-soybean meal mixed feed with and fed to pigs. J Anim Sci 95(9):3996-4004. https ://doi.org/10.2527/jas2017.1516

Su L, Cheng Y, Hsiao F, Han J, Yu Y (2018) Lactobacillus optimization of mixed solid-state fermentation of soybean meal by species and. Polish J Microbiol 67(3):297-305. https://doi.org/10.21307/pjm-2018-035

Wang L, Liu C, Chen M, Ya T, Huang W, Gao P, Zhang H (2015) A novel Lactobacillus plantarum strain P-8 activates beneficial immune response of broiler chickens. Int Immunopharmacol 29(2):901-907. https://doi.org/10.1016/j. intimp.2015.07.024
Wang C, Shi C, Su W, Jin M, Xu B, Hao L, Zhang Y, Lu Z, Wang F, Wang Y, Du H (2020) Dynamics of the physicochemical characteristics, microbiota, and metabolic functions of soybean meal and corn mixed substrates during two-stage solid-state fermentation. mSystems. https://doi.org/10.1128/ msystems.00501-19

Wongputtisin P, Khanongnuch C, Khongbantad W, Niamsup P, Lumyong S (2012) Screening and selection of Bacillus spp. for fermented corticate soybean meal production. J Appl Microbiol 113(4):798-806. https://doi. org/10.1111/j.1365-2672.2012.05395.x

Ye M, Tang X, Yang R, Zhang H, Li F, Tao F, Li F, Wang Z (2018) Characteristics and application of a novel species of Bacillus: Bacillus velezensis. ACS Chem Biol 13(3):500-505. https://doi.org/10.1021/acschembio.7b00874

Yeh R, Hsieh C, Chen K (2018) Screening lactic acid bacteria to manufacture two-stage fermented feed and pelleting to investigate the feeding effect on broilers. Poult Sci 97(1):236-246. https://doi.org/10.3382/ps/pex300

Zhang N, Yang D, Wang D, Miao Y, Shao J, Zhou X, Xu Z, Li Q, Feng H, Li S, Shen Q, Zhang R (2015) Whole transcriptomic analysis of the plant-beneficial rhizobacterium Bacillus amyloliquefaciens SQR9 during enhanced biofilm formation regulated by maize root exudates. BMC Genom 16:685. https:// doi.org/10.1186/s12864-015-1825-5

Zhang ZY, Raza MF, Zheng Z, Zhang X, Dong X, Zhang H (2018) Complete genome sequence of Bacillus velezensis $Z Y-1-1$ reveals the genetic basis for its hemicellulosic/cellulosic substrate-inducible xylanase and cellulase activities. 3 Biotech 8(11):465. https://doi.org/10.1007/s13205-018-1490-x

Zheng L, Li D, Li ZL, Kang LN, Jiang YY, Liu XY, Chi YP, Li YQ, Wang JH (2017) Effects of Bacillus fermentation on the protein microstructure and antinutritional factors of soybean meal. Lett Appl Microbiol 65(6):520-526. https://doi.org/10.1111/lam.12806

Zhu J, Gao M, Zhang R, Sun Z, Wang C, Yang F, Huang T, Qu S, Zhao L, Li Y, Hao Z (2017) Effects of soybean meal fermented by L. plantarum, B. subtilis and S. cerevisieae on growth, immune function and intestinal morphology in weaned piglets. Microb Cell Fact 16(1):191. https://doi.org/10.1186/s1293 4-017-0809-3

\section{Publisher's Note}

Springer Nature remains neutral with regard to jurisdictional claims in published maps and institutional affiliations.

\section{Submit your manuscript to a SpringerOpen ${ }^{\circ}$ journal and benefit from:}

- Convenient online submission

- Rigorous peer review

- Open access: articles freely available online

- High visibility within the field

- Retaining the copyright to your article

Submit your next manuscript at $\boldsymbol{\nabla}$ springeropen.com 